\title{
OBT and human tritium dosimetry
}

\author{
Anca Melintescu, \\ 1 "Horia Hulubei" National Institute of Physics and Nuclear Engineering, 30 Reactorului St., POB \\ MG-6, Bucharest-Magurele, RO-077125, Romania
}

Tritium $\left({ }^{3} \mathrm{H}\right)$ is a radioactive isotope of hydrogen that is ubiquitous in environmental and biological systems. Following the debate regarding the human health risk from exposure to tritium, there have been claims that the former bio kinetic model recommended by the International Commission on Radiological Protection (ICRP) may underestimate tritium doses [1]. Recently, ICRP published its new bio kinetic model for tritium [2]. In a country that develops Canada Deuterium Uranium (CANDU) reactors for production of nuclear energy, tritium is the 'national radionuclide'. Tritium can enter into the human body in many forms, but only tritiated water (HTO) and organically bound tritium (OBT) generate exposures of concern for members of the public. Based on a default OBT intake fraction of 0.5 , the new ICRP model [2] increases the tritium dose to workers by $21 \%$ comparing to the former model [1] and that could start a debate. There are some uncertainties associated with OBT metabolism as described by the ICRP's OBT model [2], particularly the retention of OBT in children and the effect of organ growth regarding the OBT retention [3]. The relative depositions of OBT in various organs and tissues are not fully known for all age groups and consequently, there is no age-dependent bio kinetic model for dietary intakes of OBT that accounts for age-related physiological and anatomical variations. HTO turnover in the human body is well understood, but the experimental data for tritium turnover in organic compounds are few, particularly for the long-term bio kinetic components.

Different physiological models regarding the OBT bio kinetics were proposed [4, 5]. A quite recent human bio kinetic model [6] considers the age and gender dependence, as well as the OBT deposition in various organs. The model was favourably tested with both HTO and OBT experimental data in urine for humans following the HTO intakes. The model was also favourably tested with OBT data in urine for humans following the OBT intake. The HTO and OBT data in urine were provided by five volunteers who ate food containing fish from Cardiff Bay, and HTO and OBT in their urine were analysed for up to 150 days [7]. After a short presentation of the model, the model tests with HTO and OBT experimental data following the OBT intake is discussed in relation with the experimental errors due to the measurement techniques. The model also predicts the dynamics of HTO and OBT in urine and blood (red blood cells and plasma) and potentially offers a new approach for bioassay. The need for a standardised bioassay technique is discussed.

\section{References}

1. ICRP 1989. Age-dependent doses to members of the public from intakes of radionuclides: Part 1. International Commission on Radiological Protection ICRP Publication 56. Ann. ICRP 20 (2) (1989)

2. ICRP 2016. Occupational Intakes of Radionuclides: Part 2. ICRP Publication 134. Ann. ICRP 45(3/4) (2016). 
3. CNSC 2010 Tritium Studies. Health effects, dosimetry and radiological protection of tritium. INFO-0799. Canadian Nuclear Safety Commission (2010), available at http://www.nuclearsafety.gc.ca//pubs_catalogue/uploads/CNSC_Health_Effects_Engweb.pdf

4. R.B. Richardson, D.W. Dunford, Health Phys. 85 (2003)

5. A. Melintescu, D. Galeriu, H. Takeda Radiat. Prot. Dosim. 127 (2007)

6. D. Galeriu, A. Melintescu, J. Radiol. Prot. 30 (2010)

7. J. Hunt, T. Bailey, A. Reese, J. Radiol. Prot. 29 (2009) 